and thrust. Within society there is a growing crisis of confidence in medicine that is multifactorial but is based partially on the factors described above. The crisis is also based on widespread economic practices in which patient welfare and the applications of science are abused for the sake of profit making.

There is a curious omission. There is no mention of medical students and medical teaching in the index, references, or the text. What does this tell us about medical school priorities? Surely teaching as well as research is a major mission of a medical school. Medical students are as important a product as data. What kind of medical students have been turned out, are being turned out, and will be turned out if we do not teach them (as well as ourselves) about our limitations as well as successes?
Perhaps a bicentennial celebration is not the time to address problems. Harvard Medical School is to be congratulated on its 200th anniversary. The school is among the best. The organisers are to be congratulated on their meeting. In many respects the volume is splendid. But it should remind us that the best is not necessarily good enough and that much remains that could be done, should be done, and must be done to reap the promised benefits of medical science for our patients.

Medicine, Science and Society. Symposia Celebrating the Harvard Medical School Bicentennial. [Harvard Medical School, 11-14 October 1982.] Ed K J Isselbacher. (Pp 768; £86.75.) John Wiley and Sons. 1984.

\title{
Bostonian neurologist
}

\author{
J D SPILLANE
}

"Why write a book about Stanley Cobb? A quarter of a century after his death in 1968 he is an almost forgotten figure, and outside the field of neurology the present generations of physicians hardly know him. He left no monumental discovery ... . and no disease or syndrome distinguishes his name." Such are the first lines of Dr White's preface. Cobb (1887-1968) was a Bostonian neurologist turned psychiatrist, who, in the author's opinion (a gastroenterologist who worked for Cobb in 1936-8), was a seminal figure in the history of the neurosciences. Cobb's publications (including reviews of books) numbered 511, the first and last being on ornithological topics. He taught neuropathology at Harvard Medical School for 35 years, established a neurological unit at the Boston City Hospital in the late 1920s, and then in 1934, to the disquiet of many, created a psychiatric service with beds in the Massachusetts General Hospital, the first in the country.

In the 'twenties Cobb made electromyographic studies in a variety of conditions - in clonus, chorea, hysteria, paralysis agitans, myasthenia gravis-and in muscular fatigue and experimental convulsions. For a decade there was a series of papers on the cerebral circulation and its possible role in epilepsy; this "appeared to reach a dead end," although it encompassed many brilliant investigations, including the use of the "cat skull window" technique devised by Forbes. It was in Cobb's laboratory that Lennox and the Gibbses made their first studies in epilepsy and were encouraged to examine the action currents of patients with epilepsy through the intact cranium in the manner of Berger.

All his life Cobb suffered from a stammer; there was a family history of the disorder. As a student he inquired about the possible therapeutic value of hypnosis and later underwent several courses of psychoanalysis in pursuit of a cure. Psychoanalysis interested him profoundly. His professional life may well have originated in his speech handicap. He became ardently devoted in his early days to the integration of neuroanatomy, neurophysiology, neuropathology, and clinical neurology and neurosurgery. With the addition of psychology and psychiatry to the medical curriculum he became a leader of the American school of psychosomatic medicine. In his psychiatric unit at Massachusetts General there were 12 beds on the same floor as neurology and neurosurgery; there were separate psychiatric clinics for adults and children.

His book Preface to Nervous Diseases (1937) he later named Fundamentals of Neuropsychiatry; there was also his Borderlands of Psychiatry, Case Histories in Psychosomatic Medicine, and Emotions and Clinical Medicine in the 'forties and 'fifties. I spent a year at the Massachusetts General in 1938-9, when Cobb was 50 . He was a tall, fine looking man, with a charming smile and manner. (Seeing a photograph of him, the actress $\mathrm{ZaZa}$ Gabor exclaimed, "My, how handsome he is.") When I first heard him lecture I was prepared for his impediment of speech but was surprised to see a pair of arthritic hands protruding from the sleeves of the long white coat he always wore. He spoke slowly and clearly, without that verbosity with which some afflicted lecturers endeavour to mask an impediment. In a New York lecture he once said, "I presume that you have noted my speech defect-I am not referring to my Harvard accent."

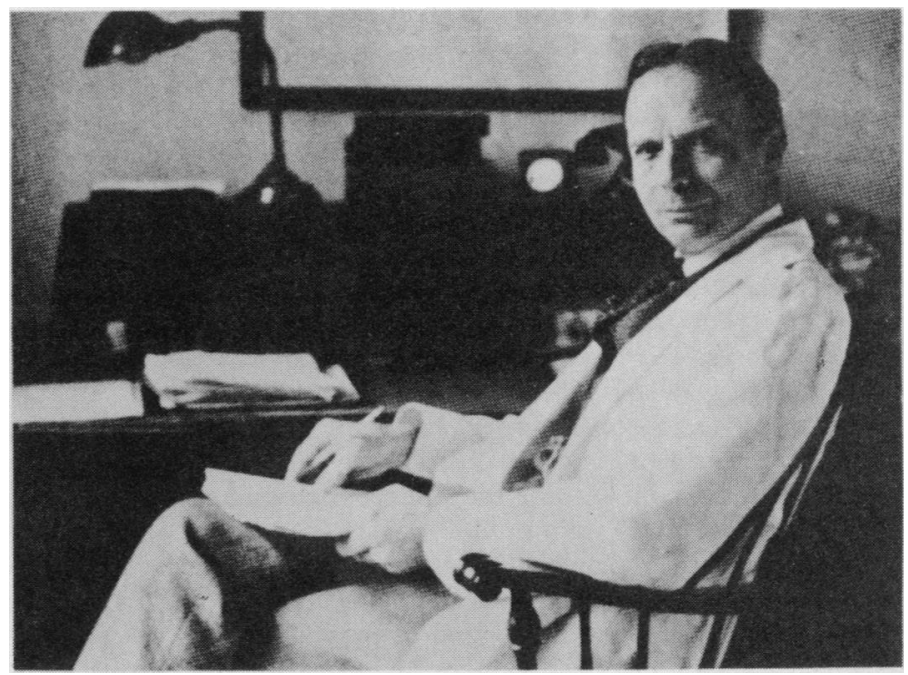

Despite his rheumatoid arthritis he led an active physical life; his hobbies were sailing, fishing, skiing, and ornithology.

This is a book of roughly 445 pages, which includes 27 pages listing his publications and another 41 pages of notes. At times overburdened with detail, the reader is likely to come away with a vivid picture of the man and his visions and ample data on which to judge whether the subtitle $A$ Builder of the Modern Neurosciences is quite justified. It is well written and a welcome addition to the illustrious history of medicine in Boston.

Stanley Cobb. A Builder of the Modern Neurosciences. B V White. (Pp $460 ; \$ 29.50$.) The Francis A Countway Library of Medicine, Boston. Distributed by the University Press of Virginia. 1984. 